\title{
Molecular mechanisms of Ellis-van Creveld gene variations in ventricular septal defect
}

\author{
FADI LIU $^{1 *}$, XIAO LIU $^{1 *}$, ZHENYAN XU $^{1}$, PING YUAN ${ }^{1}$, QIONGQIONG ZHOU ${ }^{1}$, JIEJING JIN $^{2}$, XIA YAN $^{2}$, \\ ZIXUAN XU ${ }^{1}$, QING CAO ${ }^{2}$, JIANHUA YU ${ }^{1}$, YINGZHANG CHENG $^{1}$, RONG WAN $^{2}$ and KUI HONG ${ }^{1,2}$ \\ ${ }^{1}$ Department of Cardiovascular Medicine; ${ }^{2}$ Jiangxi Key Laboratory of Molecular Medicine, \\ The Second Affiliated Hospital of Nanchang University, Nanchang, Jiangxi 330006, P.R. China
}

Received June 7, 2017; Accepted September 14, 2017

DOI: $10.3892 / \mathrm{mmr} .2017 .8088$

\begin{abstract}
The Ellis-van Creveld (EVC) gene is associated with various congenital heart diseases. However, studies on EVC gene variations in ventricular septal defect (VSD) and the underlying molecular mechanisms are sparse. The present study detected 11 single-nucleotide polymorphisms (SNPs) in 65 patients with VSD and 210 control patients from the Chinese Han population. Of the identified SNPs only the c.1727G >A SNP site was positively associated with the development of VSD $(\mathrm{P}<0.007)$. A known mutation, c. $343 \mathrm{C}>\mathrm{G}$, was also identified, which causes a leucine to valine substitution at amino acid 115 of the EVC protein (p.L115V). The results of functional prediction indicated that c. $343 \mathrm{C}>\mathrm{G}$ may be a pathogenic mutation. In addition, in NIH3T3 mouse embryonic fibroblast cells, the EVC c.343C $>\mathrm{G}$ mutation significantly decreased cell proliferation and increased apoptosis. Further investigation demonstrated that in NIH3T3 cells, overexpression of EVC c. $343 \mathrm{C}>\mathrm{G}$ mutation reduced the binding between EVC and smoothened, which further downregulated the activity of the hedgehog $(\mathrm{Hh})$ signaling pathway and the expression of downstream cyclin D1 and B-cell lymphoma 2 proteins with SAG. The c.1727G $>$ A SNP of the EVC gene increased VSD susceptibility in patients from the Chinese Han population. The molecular mechanism underlying the development of VSD induced by the EVC c.343C $>\mathrm{G}$ mutation may be due to a reduction in the anti-apoptotic and proliferative abilities of
\end{abstract}

Correspondence to: Dr Kui Hong, Department of Cardiovascular Medicine, The Second Affiliated Hospital of Nanchang University, 1 Mingde Road, Nanchang, Jiangxi 330006, P.R. China

E-mail: hongkui88@163.com

Dr Rong Wan, Jiangxi Key Laboratory of Molecular Medicine, The Second Affiliated Hospital of Nanchang University, 1 Mingde Road, Nanchang, Jiangxi 330006, P.R. China

E-mail: rong87223@163.com

${ }^{*}$ Contributed equally

Key words: Ellis-van Creveld, mutation, ventricular septal defect, congenital heart diseases cardiomyocytes via downregulation of Hh pathway activity. The results of the present study may provide novel targets for the diagnosis and treatment of patients with VSD.

\section{Introduction}

Congenital heart disease (CHD) is a common birth defect in humans and is a leading cause of non-infectious mortalities in infancy (1). Heart development at the embryonic stage is regulated by a developmental network, including signaling pathways, transcription factors and epigenetics (2-4). Gene mutations in any of these factors may cause the development of CHD (5). Ventricular septal defect (VSD) is the most common type of CHD and accounts for $\sim 30 \%$ of diagnoses (6). However, there have been few studies that focused on the underlying molecular pathogenetic mechanism of VSD. Currently, there are several known pathogenetic genes of VSD, including GATA-binding protein 4 (GATA4), GATA6, NK2 homeobox 5, T-box 1 (TBX1) and TBX5 (7). Mutations in the Ellis-van Creveld (EVC) gene may lead to EVC syndrome, and $\sim 60 \%$ of patients exhibit the cardiac septal defect phenotype which is comprised of VSD, atrial septal defect and atrioventricular septal defects $(8,9)$. Previous studies on EVC gene mutations have focused on the EVC syndrome lineage and its influence on cartilage development $(10,11)$. There appear to be no studies on EVC gene variations in patients with VSD and the potential underlying pathogenetic mechanism.

The hedgehog $(\mathrm{Hh})$ signaling pathway is a major pathway that is involved in heart development and members of this pathway include the 12-transmembrane receptor patched (Ptc), the 7-transmembrane receptor Smoothened (Smo), and the main effector factors, including members of the cubitus interruptus/glioma-associated oncogene homolog (Gli) family (12). The effector molecules in vertebrates are members of the Gli family. In the absence of Hh ligands, ligand-free Ptc represses the activity of Smo. In the presence of $\mathrm{Hh}$, binding of $\mathrm{Hh}$ to Ptc relieves Smo repression, and then Smo translocates to the membrane and is activated by phosphorylation on its carboxy-terminal tail (13). EVC is a cilia protein expressed in the second heart field (SHF) of embryos, including the outflow tract, dorsal mesenchymal protrusion and atrial septum, as well as in the atrioventricular endocardial cushions (8). In addition, EVC is an activator molecule of the $\mathrm{Hh}$ signaling 
pathway, acts downstream of Smo after it is phosphorylated and mediates $\mathrm{Hh}$ signal transduction from Smo to the Gli transcription factors $(14,15)$. Previous studies have confirmed that regulation of Hh pathway activity at the embryonic stage primarily participates in cell differentiation, proliferation and apoptosis in the SHF $(13,16,17)$. In addition, abnormal SHF development is associated with atrioventricular septal defect and various types of CHD, including VSD (16). Mutations in key $\mathrm{Hh}$ signaling genes, such as Ptc or Smo may cause embryos to present abnormal SHF development and CHD phenotypes $(16,18)$.

In the present study, it was demonstrated that the c. $1727 \mathrm{G}>\mathrm{A}$ single-nucleotide polymorphism (SNP) of EVC increased VSD susceptibility in a Chinese Han population. In addition, the EVC c.343C $>\mathrm{G}$ mutation substitution increased apoptosis and reduced proliferation through downregulation of $\mathrm{Hh}$ pathway activity in NIH3T3 mouse embryonic fibroblast cells, which may be one of the mechanisms underlying the development of VSD caused by EVC mutation. The results of the present study may provide novel targets for the diagnosis and treatment of patients with VSD.

\section{Materials and methods}

Study population. A total of 65 patients with VSD (40 males and 25 females) aged from 2 to 71 years and 210 healthy controls (121 males and 89 females) aged from 3 to 68 years were recruited from January 2008 to December 2010 in The Second Affiliated Hospital of Nanchang University (Nanchang, China). The patients with VSD were diagnosed based on physical examination, chest radiography, electrocardiograms and echocardiography, and confirmed by cardiac catheterization or cardiac surgery. The healthy controls were excluded from having $\mathrm{CHD}$ by the cardiac echocardiography. All participants were from the same ethnicity of Chinese Han population. The present study was approved by The Human Ethics Committee of the Second Affiliated Hospital of Nanchang University, and written informed consent was signed by the patients or their guardians prior to the present study.

Cell culture. NIH3T3 cells were purchased from the Type Culture Collection of Chinese Academy of Sciences (Shanghai, China) and cultured in high glucose Dulbecco's modified Eagle's medium (DMEM; Gibco; Thermo Fisher Scientific, Inc., Waltham, MA, USA) supplemented with $10 \%$ fetal bovine serum (Gibco; Thermo Fisher Scientific, Inc.), $100 \mathrm{U} / \mathrm{ml}$ penicillin and $100 \mu \mathrm{g} / \mathrm{ml}$ streptomycin at $37^{\circ} \mathrm{C}$ in a $5 \% \mathrm{CO}_{2}$ incubator.

Reagents and materials. The TIANamp Blood DNA kit (DP332) and 2X PCR Taq MasterMix (KT201) was obtained from Tiangen Biotech Co., Ltd. (Beijing, China). Recombinant adenoviruses (CMV-MCS-SV40-GFP) EVC-wild-type (WT)-green fluorescent protein (GFP) and EVC-343C $>$ G-GFP (mutation, Mut), and the Gli2-Flag plasmid were purchased from Shanghai GeneChem Co., Ltd. (Shanghai, China). An empty vector was used for control (data not shown). The sequence of the Gli2 was derived from the Nucleotide database at the National Center for Biotechnology Information (NM_005270.4). The EVC-WT group was used as the control and treated with the adenoviruses EVC-wild-type (WT)-green fluorescent protein. The Smo agonist (SAG; cat. no. 566661) was purchased from Sigma-Aldrich; Merck KGaA (Darmstadt, Germany). Rabbit anti-B cell lymphoma 2 (Bcl2; cat. no. 12789-1-AP), rabbit anti-B-cell lymphoma 2-associated X protein (Bax; cat. no. 50599-2-Ig), mouse anti-Flag (cat. no. 66008-2-Ig) and rabbit anti- $\beta$-tubulin antibodies (cat. no. 10068-1-AP) were all purchased from ProteinTech Group, Inc. (Chicago, IL, USA); anti-Gli1 (cat. no. 2643) antibody was obtained from Cell Signaling Technology, Inc. (Danvers, MA, USA); rabbit anti-cyclin D1 (cat. no. ab134175), rabbit anti-Smo (cat. no. ab72130) and rabbit anti-Ki67 (cat. no. ab15580) antibodies were all purchased from Abcam (Cambridge, UK); rabbit anti-EVC (cat. no. SAB1405772) was obtained from Sigma-Aldrich; Merck KGaA. The 5-ethynyl-20-deoxyuridine (EdU) assay was obtained from Guangzhou RiboBio Co., Ltd. (Guangzhou, China). Terminal deoxynucleotidyl transferase dUTP nick-end labeling (TUNEL) assay was purchased from Beyotime Institute of Biotechnology (Haimen, China). Protein A/G plus-agarose was obtained from Santa Cruz Biotechnology, Inc. (Dallas, TX, USA).

Genetic screening of EVC. Genomic DNA was extracted from $2 \mathrm{ml}$ blood samples obtained from all participants with a TIANamp Blood DNA kit. All exons and exon-intron boundaries of the EVC gene were generated by polymerase chain reaction (PCR). The specific PCR primers were designed using Primer Premier 5.0 software (Premier Biosoft International, Palo Alto, CA, USA). Primers, region, fragment sizes were given in the Table I. The PCR was carried out in a total volume of $16 \mu \mathrm{l}$ solution containing $50 \mathrm{ng}$ template DNA, $200 \mathrm{nM}$ of each primer, 2X Taq PCR MasterMix $8 \mu \mathrm{l}$. The thermocycling conditions were as follows: One cycle of $5 \mathrm{~min}$ at $94^{\circ} \mathrm{C} ; 20$ cycles of $15 \mathrm{sec}$ at $94^{\circ} \mathrm{C}, 30 \mathrm{sec}$ at $65^{\circ} \mathrm{C}$ $\left(-0.5^{\circ} \mathrm{C} /\right.$ cycle); 10 cycles of $15 \mathrm{sec}$ at $94^{\circ} \mathrm{C}$ and $30 \mathrm{sec}$ at $55^{\circ} \mathrm{C}$. The amplicons were bi-directionally sequenced with a 3130 XL DNA analyzer (Applied Biosystems; Thermo Fisher Scientific, Inc.). Sequences were aligned and compared with the reference EVC gene (GenBank ID: NG_008843.1). For the identified gene variations, the dbSNP (https://www. ncbi.nlm.nih.gov/projects/SNP), the 1000 Genomes Project (http://www.1000genomes.org), the Exome Variant Server (EVS; http://evs.gs.washington.edu/EVS) and the Exome Aggregation Consortium (Ex AC; http://exac.broadinstitute.org) databases were investigated in the present study. The Polymorphism Phenotyping version 2 (PolyPhen-2; http:/genetics.bwh.harvard.edu/pph2), Sorting Intolerant from Tolerant (SIFT; http://sift.bii.astar.edu.sg/) and MutationTaster (http://www.mutationtaster.org) programs were used to evaluate the disease-causing potential of detected EVC variants.

Cell transfection and treatments. Cells were grown to 80-90\% confluence in 35-mm dishes and transfected with Gli2-Flag plasmids using Lipofectamine ${ }^{\mathrm{TM}}$ LTX (A12621; Invitrogen; Thermo Fisher Scientific, Inc.) and adenovirus harboring EVC-WT-GFP or EVC-343C $>$ G-GFP $(\mathrm{MOI}=50)$ were added directly to cells for $48 \mathrm{~h}$ at $37^{\circ} \mathrm{C}$. The efficacy of transfection was determined using immunofluorescence microscopy. Cells were treated with SAG $(200 \mathrm{nM}) 24 \mathrm{~h}$ post-transfection when required at $37^{\circ} \mathrm{C}$. 
Table I. Primers used to amplify the exons and exon-intron boundaries of the EVC gene.

\begin{tabular}{lllr}
\hline Coding exon & \multicolumn{1}{c}{ Forward primer (5'-3') } & \multicolumn{1}{c}{ Reverse primer (5'-3') } & Size (bp) \\
\hline 1 & TCTGTCTCTGGGCATGCTCAG & AAGTTCCCAACCAGGCTCAAG & 550 \\
2 & AGCAGAAGTGGCTGCTGGACTG & CTATATCTGTCAGAGGCTTGTC & 345 \\
3 & TCTGAGGCTGCTATTACAAATG & CATGTCCTGTCCTGAGCCTC & 353 \\
4 & CTAGCGTGAATCACTGGTAG & CAGAGTCACTGAACCTCTCTG & 433 \\
5 & ATTACCTCAGCATGCTGCAG & CACTGATGTCTGCCTCTCAAG & 329 \\
6 & ATCGGAGTTCCTTTCCTTCAG & CTCTTTGAGTAGTAGATATGAC & 508 \\
7 & GTCAAACCTCATGTACAAC & CTTCTAACTATCATCTCTC & 380 \\
8 & GAGCACGCACCGTTTGGCTTC & GATGTCAAGCCTCAGGATTC & 303 \\
9 & CTGGTGGCTTCTTCTCAGCTG & CAGAAGCAGAAAGGCAGCCTG & 435 \\
10 & CTGGCTCACAGAGTCACCTC & CACCAGCTTACAGTCCACTAG & 389 \\
11 & CAGCTGTGAAAGCCATGTGAC & GACACAGCCTGCGTGGATCAC & 413 \\
12 & CCTGTCTGTGGATCTCCTTG & CAGTCATCTCCGTAGAGCACC & 456 \\
13 & CCACATGCCTGCTCTGTCC & CTATGACAGACAACTCTATC & 347 \\
14 & CACCCATGCCTAAGAGGATG & GCACCAAGGGTGATAGGATTC & 472 \\
15 & GAGCTTCTCTGTGAGAGGAG & CAAGTCATGGAGAAGTCAG & 399 \\
16 & GATAGGATTCCCATGACTAG & GCACACATTGCCAGTCTCTTC & 377 \\
17 & CACTCTTGGAGAGCTGGTG & CACAGAGAGATATGCCATGTG & 294 \\
18 & CACTTTGATGGAGAGGCAGCCTG & CTGACGTGTGGTCACAGGCTG & 403 \\
19 & GCAGCAGGAGCTGGTAGATG & GATGCCTAAGGTCACACAGCTAG & 393 \\
20 & CCTCATTAGTTGAGTGGCTG & CAAACCCAGCCACAGGCAACAG & 312 \\
21 & GTCATGGCACTTGGATGACCTC & CTGCCTCTCAGCACTGCAGGAG & 363 \\
\hline
\end{tabular}

Western blotting and immunoprecipitation. Western blotting was performed as previously described (19). In brief, when grown to $80-90 \%$ confluence, $200 \mu \mathrm{l}$ radioimmunoprecipitation assay buffer (RIPA; P0013B) and $1 \mathrm{mM}$ PMSF (ST506) (both from Beyotime Institute of Biotechnology, Beijing, China) were used to lyse the cells. Total protein was extracted and determined by bicinchoninic acid (BCA) assay before loading the samples into wells. The proteins $(40 \mu \mathrm{g})$ were separated via $8 \%$ SDS-PAGE and then were transferred to a polyvinylidene fluoride (PVDF) membrane (ISEQ00010; EMD Millipore, Billerica, MA, USA) via electroblotting. Following blocking with the 5\% defatted milk, the membrane was incubated with primary antibody at $4{ }^{\circ} \mathrm{C}$ over night and then incubated with the goat anti-mouse immunoglobulin $G$ ( $\mathrm{IgG}$ ) horseradish peroxidase (HRP)-conjugated antibody and goat anti-rabbit IgG HRP conjugate $(1: 6,000$, cat. nos. HS201-01, HS101-01, respectively; Beijing TransGen Biotech Co., Ltd. Beijing, China). The protein bands were visualized by chemiluminescence (PA112-01; Tiangen Biotech Co., Ltd.). Primary antibodies used were: Mouse anti-Gli1 (1:1,000), rabbit anti-Bcl2 (1:500), rabbit anti-Bax (1:500), mouse anti-Flag $(1: 1,000)$, rabbit anti-cyclin D1 $(1: 1,000)$, rabbit anti-EVC $(1: 1,000)$, rabbit anti-Smo $(1: 1,000)$ and rabbit anti- $\beta$-tubulin $(1: 1,000)$. Band intensities were analyzed by Image Lab software version 2.2 (Bio-Rad Laboratories, Inc., Hercules, CA, USA).

Immunoprecipitation experiments were as performed as previously described (19). Cells were lysed with addition of $0.5 \mathrm{ml}$ RIPA buffer. The supernatant was obtained following centrifugation at $14,000 \mathrm{x}$ g for $15 \mathrm{~min}$. The primary antibody
Smo (1:200) was added and then, protein A/G plus-Agarose was added and incubated over night. The immunoprecipitate was collected by centrifugation at 3,500 x g for $10 \mathrm{~min}$. The pellet was then washed four times and resuspended in $40 \mu \mathrm{l}$, $2 \mathrm{X}$ loading buffer. All the above steps were performed at $4^{\circ} \mathrm{C}$. The samples were boiled and analyzed by SDS-PAGE. Experiments were performed in triplicate.

EdU and TUNEL assays. EdU experiments were performed as previously described (20). NIH3T3 cells were seeded in 96-well plates at $1 \times 10^{4}$ cells/well, The cells were grown to $80-90 \%$ and then incubated with EdU for $2 \mathrm{~h}$, and processed according to the manufacturer's instructions. Following three washes with PBS, the cells were treated with $300 \mu 1$ 1X Apollo ${ }^{\circledR}$ reaction cocktail for $30 \mathrm{~min}$ at room temperature. Then, the DNA contents of the cells in each well were stained with $100 \mu$ l Hoechst 33342 (R11053.4; Guangzhou RiboBio Co., Ltd., Guangzhou, China) for $30 \mathrm{~min}$ at room temperature and visualized under a fluorescence microscope (Nikon Eclipse 90i; Nikon Corporation, Toyko, Japan). A total of five fields were examined/group.

The TUNEL assay was performed as previously described (21). NIH3T3 cells were grown to 70-80\% and pretreated with $200 \mu \mathrm{M} \mathrm{H}_{2} \mathrm{O}_{2}$ for $24 \mathrm{~h}$ at $37^{\circ} \mathrm{C}$. TUNEL assays were performed in following the manufacturer's instructions. Positive apoptotic cells were stained brown for incubation for $30 \mathrm{~min}$ at room temperature using TUNEL kit and nuclei were counterstained with hematoxylin at room temperature for $2 \mathrm{~min}$. The cells were visualized with an optical microscope, five fields were examined/group. 
Table II. Hardy-Weinberg equilibrium test of Ellis-van Creveld variations in controls and patients with VSD.

\begin{tabular}{|c|c|c|c|c|c|c|c|c|}
\hline \multirow{2}{*}{$\frac{\text { Variation }}{\text { c. } 221 \mathrm{~A}>\mathrm{C}}$} & \multirow{2}{*}{$\begin{array}{l}\text { Genotype } \\
\text { Genotype }\end{array}$} & \multirow[t]{2}{*}{$\mathrm{n}$} & \multicolumn{3}{|c|}{ Genotype frequency $(\%)$} & \multicolumn{2}{|c|}{ Allele frequency $(\%)$} & \multirow[t]{2}{*}{$\mathrm{HWE}^{\mathrm{a}}$ (P-value) } \\
\hline & & & AA & $\mathrm{AC}$ & $\mathrm{CC}$ & $\mathrm{C}$ & A & \\
\hline \multirow[t]{2}{*}{ p.Q74P } & VSD & 64 & $50(78.1)$ & $13(20.3)$ & $1(1.6)$ & $15(11.7)$ & $113(88.3)$ & 0.884 \\
\hline & Control & 201 & $131(65.2)$ & $61(30.3)$ & $9(4.5)$ & $79(19.7)$ & $323(80.3)$ & 0.580 \\
\hline c. $343 \mathrm{C}>\mathrm{G}$ & Genotype & & $\mathrm{CC}$ & CG & GG & $\mathrm{C}$ & G & \\
\hline \multirow[t]{2}{*}{ p.L115V } & VSD & 61 & $60(98.4)$ & $1(1.6)$ & $0(0.0)$ & $121(99.2)$ & $1(0.8)$ & \\
\hline & Control & 210 & $210(100.0)$ & $0(0.0)$ & $0(0.0)$ & $420(100)$ & $0(0)$ & \\
\hline c. $772 \mathrm{~T}>\mathrm{C}$ & Genotype & & $\mathrm{CC}$ & $\mathrm{TC}$ & $\mathrm{TT}$ & $\mathrm{T}$ & $\mathrm{C}$ & \\
\hline \multirow[t]{2}{*}{ p.Y258H } & VSD & 60 & $51(85.0)$ & $9(15.0)$ & $0(0.0)$ & $9(7.5)$ & $111(92.5)$ & 0.530 \\
\hline & Control & 200 & $172(86.0)$ & $28(14.0)$ & $0(0.0)$ & $28(7.0)$ & $372(93.0)$ & 0.287 \\
\hline c. $969 \mathrm{~T}>\mathrm{C}$ & Genotype & & $\mathrm{CC}$ & $\mathrm{TC}$ & TT & $\mathrm{T}$ & $\mathrm{C}$ & \\
\hline \multirow[t]{2}{*}{ p.N323N } & VSD & 63 & $26(41.3)$ & $31(49.2)$ & $6(95.2)$ & $43(34.1)$ & $83(65.9)$ & 0.454 \\
\hline & Control & 210 & 75 (35.7) & $94(44.8)$ & $41(19.5)$ & $176(41.9)$ & $244(58.1)$ & 0.242 \\
\hline c. $1026 \mathrm{G}>\mathrm{C}$ & Genotype & & $\mathrm{CC}$ & GC & GG & G & C & \\
\hline \multirow[t]{2}{*}{ p.L342L } & VSD & 63 & $25(39.7)$ & 30 (47.6) & $8(12.7)$ & $46(36.5)$ & $80(63.5)$ & 0.829 \\
\hline & Control & 210 & $85(40.5)$ & $85(40.5)$ & $40(19.0)$ & $165(39.3)$ & $255(60.7)$ & $0.028^{\mathrm{b}}$ \\
\hline c. $1068 \mathrm{~A}>\mathrm{G}$ & Genotype & & AA & AG & GG & G & A & \\
\hline \multirow[t]{2}{*}{ p.L356L } & VSD & 63 & $42(66.7)$ & $19(30.2)$ & $2(3.2)$ & $23(18.3)$ & $103(81.7)$ & 0.933 \\
\hline & Control & 210 & $128(61.0)$ & $66(31.4)$ & $16(7.6)$ & $98(23.3)$ & $322(76.7)$ & 0.078 \\
\hline c. $1346 \mathrm{C}>\mathrm{A}$ & Genotype & & AA & $\mathrm{CA}$ & $\mathrm{CC}$ & $\mathrm{C}$ & A & \\
\hline \multirow[t]{2}{*}{ p.T449K } & VSD & 64 & $45(70.3)$ & $19(29.7)$ & $0(0.0)$ & $19(14.8)$ & $109(85.2)$ & 0.163 \\
\hline & Control & 207 & $142(68.6)$ & $49(23.7)$ & $16(7.7)$ & 81 (19.6) & $333(80.4)$ & $<0.001^{\mathrm{b}}$ \\
\hline c. $1320 \mathrm{~T}>\mathrm{A}$ & Genotype & & $\mathrm{TT}$ & $\mathrm{TA}$ & AA & A & $\mathrm{T}$ & \\
\hline \multirow[t]{2}{*}{ p.F440L } & VSD & 62 & $56(90.3)$ & $6(9.7)$ & $0(0.0)$ & $6(4.8)$ & $118(95.2)$ & 0.689 \\
\hline & Control & 207 & $179(86.5)$ & $22(10.6)$ & $6(2.9)$ & $34(8.2)$ & $380(91.8)$ & $<0.001^{\mathrm{b}}$ \\
\hline c. $1333 \mathrm{~A}>\mathrm{C}$ & Genotype & & AA & $\mathrm{AC}$ & $\mathrm{CC}$ & $\mathrm{C}$ & A & \\
\hline \multirow[t]{2}{*}{ p.K445Q } & VSD & 63 & $60(95.2)$ & $3(4.8)$ & $0(0.0)$ & $3(2.4)$ & $123(97.6)$ & 0.847 \\
\hline & Control & 207 & $196(94.7)$ & $8(3.9)$ & $3(1.4)$ & $14(3.4)$ & 400 (96.6) & $<0.001^{\mathrm{b}}$ \\
\hline c. $1727 \mathrm{G}>\mathrm{A}$ & Genotype & & GG & GA & AA & A & G & \\
\hline \multirow[t]{2}{*}{ p.R576Q } & VSD & 52 & $10(19.2)$ & $36(69.2)$ & $6(11.5)$ & 48 (46.2) & $56(53.8)$ & 0.005 \\
\hline & Control & 174 & $87(50.0)$ & $71(40.8)$ & $16(9.2)$ & 103 (29.6) & $245(70.4)$ & 0.783 \\
\hline c. $1854 \mathrm{C}>\mathrm{T}$ & Genotype & & $\mathrm{TT}$ & $\mathrm{CT}$ & $\mathrm{CC}$ & $\mathrm{C}$ & $\mathrm{T}$ & \\
\hline \multirow[t]{2}{*}{ p.G618G } & VSD & 65 & $13(0.2)$ & $31(47.7)$ & $21(32.3)$ & $73(56.2)$ & $57(43.8)$ & 0.780 \\
\hline & Control & 185 & $57(30.8)$ & $87(47.0)$ & $41(22.2)$ & $169(45.7)$ & $201(54.3)$ & 0.476 \\
\hline c. $2279 \mathrm{G}>\mathrm{A}$ & Genotype & & GG & GA & AA & A & G & \\
\hline \multirow[t]{2}{*}{ p.R760Q } & VSD & 62 & 55 (88.7) & $6(9.7)$ & $1(1.6)$ & $8(6.5)$ & $116(93.5)$ & 0.119 \\
\hline & Control & 200 & $167(83.5)$ & $33(16.5)$ & $0(0.0)$ & $33(8.3)$ & 367 (92.7) & 0.204 \\
\hline
\end{tabular}

${ }^{a} \mathrm{HWE}$ test of EVC variations in controls and patients with VSD; only one genotype was detected in the c.343C $>\mathrm{G}$ control samples in which HWE was not calculated; ${ }^{b} \mathrm{HWE} \mathrm{P}<0.05$ in the control group was excluded. HWE, Hardy-Weinberg equilibrium; SNP, single-nucleotide polymorphism; VSD, ventricular septal defect.

Dual-luciferase reporter assay. A dual luciferase reporter assay was performed as previously described (22). In brief, the NIH3T3 cells were seeded at a density of $1 \times 10^{5}$ cells/well in 6 -well plates. Following incubation for $24 \mathrm{~h}$, the cells were transfected with adenoviruses EVC-WT-GFP and EVC-Mut-GFP. The cells were incubated for $48 \mathrm{~h}$ prior to transfection with the Gli1-luciferase reporter $(5 \mu \mathrm{g})$ using Lipofectamine $^{\text {TM }}$ LTX (A12621; Invitrogen; Thermo Fisher Scientific, Inc.) according to the manufacturer's instructions. SAG was added and incubated for $24 \mathrm{~h}$ before harvesting. Gli1 transcriptional activity was calculated as the ratio between firefly and Renilla luciferase units. The assay was performed using the Dual-Luciferase ${ }^{\circledR}$ Reporter Assay System (E1910; Promega Corporation, Madison, WI, USA).

Immunofluorescence staining. Immunofluorescence was performed as previously described (23). In brief, the NIH3T3 cells were seeded in 6-well plates at a density of $1 \times 10^{5}$ cells/well. The cells were grown to $70-80 \%$ and fixed with $4 \%$ paraformaldehyde at room temperature for $20 \mathrm{~min}$ before blocking with 5\% bull serum albumin (BSA; 10099158; Invitrogen; Thermo Fisher Scientific, Inc.) at room temperature 
Table III. Associations between EVC SNPs and VSD risk.

\begin{tabular}{|c|c|c|c|c|}
\hline SNP & Model & Comparison & P-value ${ }^{a}$ & OR $(95 \% \mathrm{CI})$ \\
\hline \multirow[t]{5}{*}{ c. $221 \mathrm{~A}>\mathrm{C}$} & Heterozygous & AC vs. AA & 0.091 & $0.559(0.282-1.104)$ \\
\hline & Homozygous & CC vs. AA & 0.390 & $0.291(0.036-2.358)$ \\
\hline & Dominant & $\mathrm{AC}+\mathrm{CC}$ vs. AA & 0.053 & $0.524(0.271-1.014)$ \\
\hline & Recessive & $\mathrm{CC}$ vs. $\mathrm{AC}+\mathrm{AA}$ & 0.491 & $0.339(0.042-2.727)$ \\
\hline & Allele & C vs. A & 0.041 & $0.543(0.300-0.981)$ \\
\hline \multirow[t]{5}{*}{ c. $1727 \mathrm{G}>\mathrm{A}$} & Heterozygous & GA vs. GG & $<0.001$ & $4.411(2.047-9.506)$ \\
\hline & Homozygous & AA vs. GG & 0.035 & $3.263(1.039-10.24)$ \\
\hline & Dominant & $\mathrm{GA}+\mathrm{AA}$ vs. GG & $<0.001$ & $4.200(1.982-8.901)$ \\
\hline & Recessive & AA vs. GA+GG & 0.617 & $1.288(0.477-3.481)$ \\
\hline & Allele & A vs. G & 0.002 & $2.039(1.301-3.195)$ \\
\hline \multirow{5}{*}{ c. $1854 \mathrm{C}>\mathrm{T}$} & Heterozygous & CT vs. TT & 0.228 & $1.562(0.754-3.238)$ \\
\hline & Homozygous & CC vs. TT & 0.045 & $2.246(1.009-4.998)$ \\
\hline & Dominant & $\mathrm{CC}+\mathrm{CT}$ vs. TT & 0.095 & $1.781(0.899-3.528)$ \\
\hline & Recessive & CC vs. CT+TT & 0.103 & $1.676(0.897-3.132)$ \\
\hline & Allele & C vs. T & 0.040 & $1.523(1.019-2.278)$ \\
\hline
\end{tabular}

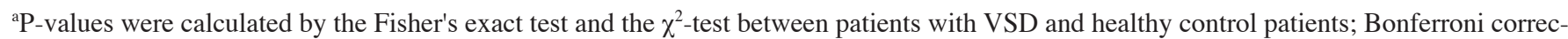
tion was performed and $\mathrm{P}<0.05 / 7=0.007$ considered significant. $\mathrm{CI}$, confidence interval; OR, odds ratio; SNP, single-nucleotide polymorphism; VSD, ventricular septal defect.

for $20 \mathrm{~min}$. Following incubation with the primary antibody anti-Ki67 (1:50) at $4^{\circ} \mathrm{C}$ overnight, the cells were then washed and incubated again with fluorescein isothiocyanate-conjugated donkey anti-rabbit immunoglobulin $\mathrm{G}$ (1:200) and DAPI $(0.1 \mathrm{mg} / \mathrm{ml})$ at $37^{\circ} \mathrm{C}$ for $1 \mathrm{~h}$. The image was visualized using a fluorescence microscope (Nikon Eclipse 90i; Nikon Corporation) following DAPI staining. A total of five fields were examined/group. The percentage of Ki67-positive cells was calculated.

Statistical analysis. Statistical analysis was performed with SPSS version 20.0 statistical software (IBM Corp., Armonk, NY, USA). The genetic balance of SNP genotypes was tested according to the Hardy-Weinberg equilibrium (24). Allele and genotype frequencies in the cases and controls were compared using $\chi^{2}$ tests. Genetic data were corrected for multiple comparisons using the Bonferroni correction test. Risk prediction for VSD was expressed as odds ratio and $95 \%$ confidence interval (CI). Continuous data were presented as the mean \pm standard error of the mean. The differences between groups were analyzed using Student's t-test or one-way analysis of variance followed by Tukey's post hoc test. $\mathrm{P}<0.05$ was considered to indicate a statistically significant difference.

\section{Results}

Analysis of EVC SNPs in patients with VSD. Through sequencing and screening of the EVC gene, 11 EVC SNP sites were detected in patients with VSD, including c.221 A $>C$ (p.Q74P), c.772T >C (p.Y258H), c.969T >C (p.N323N), c.1026G $>$ C (p.L342L), c.1068A >G (p.L356L), c.1320T >A (p.F440L), c.1333A>C p.K445Q), c.1346C >A (p.T449K), c.1727G >A (p.R576Q), c.1854C $>$ T (p.G618G) and c.2279G $>$ A
(p.R760Q). The detection results of the genotype distribution, allele frequency and Hardy-Weinberg equilibrium of all the sites are provided in Table II. Four of the SNPs (c.1026G $>$ C, c.1320T $>$ A, c.1333A $>$ C and c.1346C $>$ A) were excluded for the association analysis owing to deviation from the Hardy-Weinberg equilibrium. The remaining seven SNPs were analyzed under five genetic models, including homozygous, heterozygous, dominant, recessive and allele (Table III). The results revealed that the $\mathrm{C}$ allele of SNP c. $221 \mathrm{~A}>\mathrm{C}$ was negatively associated with the risk of VSD development $(\mathrm{OR}=0.543 ; \mathrm{CI}=0.300-0.981 ; \mathrm{P}=0.041)$. The risk of VSD development in patients carrying the CC genotype of the $\mathrm{c} .1854 \mathrm{C}>\mathrm{T}$ site was 2.246 times higher compared with the risk in patients carrying the TT genotype $(\mathrm{CI}=1.009-4.998$; $\mathrm{P}=0.045)$. The $\mathrm{C}$ allele was the risk allele of $\mathrm{VSD}(\mathrm{OR}=1.523$; $\mathrm{CI}=1.019-2.278 ; \mathrm{P}=0.040)$. Only the $\mathrm{c} .1727 \mathrm{G}>\mathrm{A}$ site was significantly positively associated with the development of VSD following Bonferroni correction $(\mathrm{P}<0.007)$, indicating that the risk of VSD in people carrying the GA genotype was 4.411 times higher compared with the risk in people carrying the GG genotype ( $\mathrm{CI}=2.047-9.506)$. In addition, in the dominant model, the risk of VSD in people carrying the GA or AA genotype was 4.2 times higher compared with people carrying the $\mathrm{GG}$ genotype $(\mathrm{CI}=1.982-8.901)$. The $\mathrm{A}$ allele in $\mathrm{c} .1727 \mathrm{G}>\mathrm{A}$ was the risk allele of $\operatorname{VSD}(\mathrm{OR}=2.039$; $\mathrm{CI}=1.301-3.195$; $\mathrm{P}=0.002$ ). Differences in the distribution of the four other SNP sites in the five models did not have statistical significance ( $\mathrm{P}>0.05$; data not shown).

The results of gene variants function predictions using PolyPhen-2, SIFT and MutationTaster software demonstrated that the SNP c.1727G $>$ A may cause an alteration in the splicing site, thus resulting in the development of the disease (data not shown). 
Importantly, a heterozygous nonsynonymous mutation was identified using the direct DNA sequencing method in a patient with VSD (Fig. 1); however, DNA from family members was not available. Sequencing confirmed that it was c.343C $>$ G, which caused a change from leucine to valine (p.L115V; Fig. 1B), which was not found in 420 normal chromosomes. This mutation was not reported in the 1000 Genomes database and EVS database, whereas in the ExAC database, its minor allele frequency (MAF) was 0.0002 . The prediction results of the c.343C $>\mathrm{G}$ site revealed the possibility of a pathogenic mutation (data not shown). Comparison of the EVC coding region sequences among different species demonstrated that the EVC-L115V substitution site was highly conserved among different species (Fig. 1C). Therefore, the EVC c.343C > G SNP was selected for subsequent functional analysis.

Reduction of NIH3T3 cell proliferation by the EVC c.343C $>G$ mutation. It has been previously reported that blocking Hh pathway activity may affect cell proliferation levels in the SHF (25); following EVC knockout, proliferation of cartilage cells in mice was also inhibited (11). To clarify whether the EVC c.343C $>\mathrm{G}$ mutation affected proliferation, the cell proliferation marker Ki67 was used to observe the proliferation levels of NIH3T3 cells. The results indicated that the percentage of Ki67-stained cells among the total cells in the Mut group was significantly decreased compared with the WT group in the presence of the Smo agonist SAG $(23 \pm 1.3$ vs. $30.4 \pm 1.8 \%$, respectively; $\mathrm{P}<0.05$; Fig. $2 \mathrm{~A}$ and $\mathrm{B}$ ).

In addition, the effects of the EVC mutation on cell proliferation were further validated using an EdU assay. The results revealed that the percentage of EdU-labeled S-phase cells in the Mut group was significantly decreased compared with that in the WT group in the presence of SAG (12.5 \pm 0.8 vs. $15.6 \pm 0.4 \%$, respectively; $\mathrm{P}<0.05$; Fig. $2 \mathrm{C}$ and $\mathrm{D})$, suggesting that the EVC c.343C $>\mathrm{G}$ mutation may cause an abnormal cell cycle transition from the G1 to the S phase in NIH3T3 cells, therefore affecting their proliferation.

In the Hh signaling pathway, EVC may influence cell proliferation by regulating the expression of cyclin D1 (26). In the present study, western blotting results demonstrated that during the activation of the Hh pathway following SAG treatment, the expression of cyclin D1 in the Mut group was significantly decreased compared with expression in the WT group (Fig. 2E and F), which suggested that the cells were arrested during their progression from G1 phase to S phase of the cell cycle.

Increase in apoptosis in NIH3T3 cells by the EVC c.343C >G mutation treated with $S A G$. A previous study demonstrated that Hh signaling pathway may protect the astrocytes from oxidative stress by activating PI3-K/AKT/Bcl-2 pathway (27). NIH3T3 cell were treated with $\mathrm{H}_{2} \mathrm{O}_{2}$ and the cell apoptosis was detected by TUNEL to observe whether the EVC mutation affected cell apoptosis. The results of the present study indicated that NIH3T3 cells apoptosis in the Mut group was significantly higher compared with that in the WT group in the presence of SAG $(15.0 \pm 0.7$ vs. $7.5 \pm 0.6 \%$; Fig. $3 \mathrm{~A}$ and $\mathrm{B})$.

In addition, the protein expression levels of $\mathrm{Bcl} 2$ and $\mathrm{Bax}$ in cells transfected with either EVC-WT or EVC-Mut was measured by western blotting following $\mathrm{H}_{2} \mathrm{O}_{2}$ induction. The

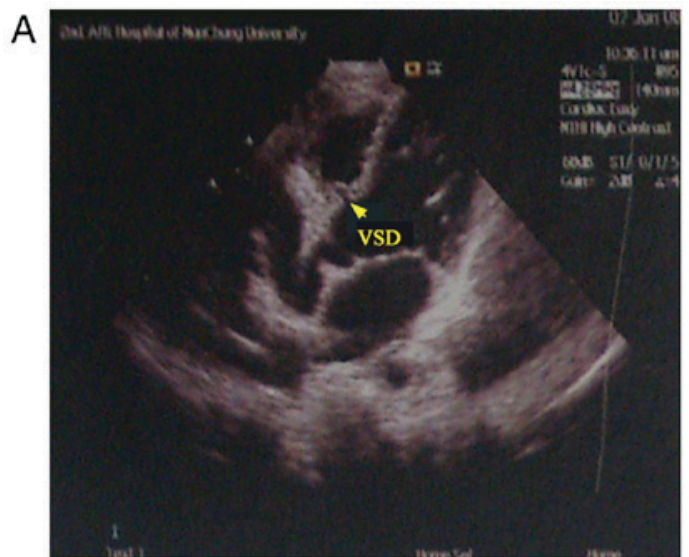

$B G C A T T C G \subset C \underline{C T G} A A G G C \subset A A A$ Mut EVC c.343C $>$ G, p.L115V

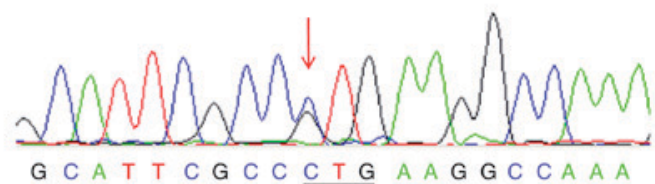

$G C A T T C G C C$ C T G A A G C C A A A

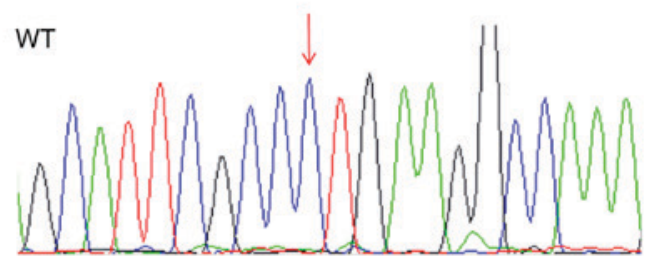

C

Human NITAFALKAKVIYPINQK 126

Mouse NITAFALKARVVYPINQK 121

Rat NITAFALKARVVYPINQK 119

Macaque NITAFALKAKVIYPINQK 126

Canine NITAFALKAKVIYPINQK 125

Cattle NITAFALKAKVVYPINQK 126

Goat NITAFALKAKVVYPINQK 126

Figure 1. Detection of the c.343C $>\mathrm{G}$ mutation in EVC gene. (A) An echocardiogram of a VSD patient who carried the EVC c.343C $>\mathrm{G}$ mutation. The yellow arrow points to the site of VSD. (B) Sequence chromatograms indicating the EVC heterozygous Mut of c.343C $>$ G (p.L115V) and its WT control. The upper red arrow indicates the heterozygous nucleotides of C/G. (C) Amino acid sequence alignment of the substitution location across multiple species. The p.L115V (highlighted) site is located in a highly conserved amino acid of the EVC protein. EVC, Ellis-van Creveld; Mut, EVC c.343C>G mutation; VSD, ventricular septal defect; WT, wild-type.

results demonstrated that when the Hh pathway was activated by SAG treatment, Bcl2 protein expression decreased and Bax expression increased in the EVC-Mut group compared to the EVC-WT group (Fig. 3C), and the protein expression ratio of $\mathrm{Bcl} 2 / \mathrm{Bax}$ was significantly lower in the Mut group compared to the WT group $(\mathrm{P}<0.05$; Fig. 3D), which suggested that EVC c.343C $>$ G mutation may reduce the anti-apoptotic activity of NIH3T3 cells.

Downregulation of Hh pathway activity by the EVC c.343C>G mutation. EVC is an important activator of the 
A

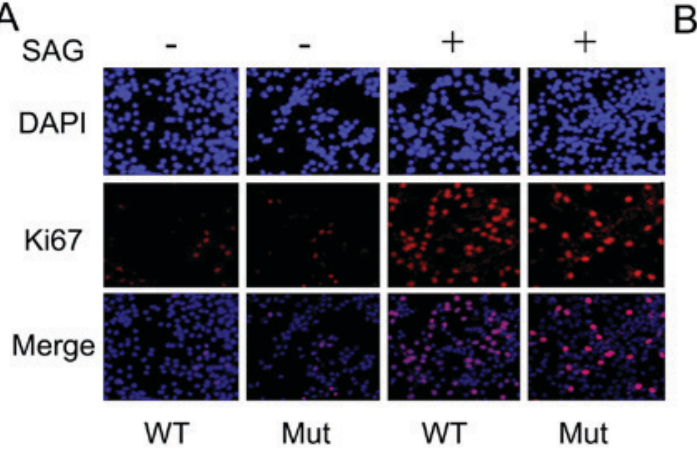

C
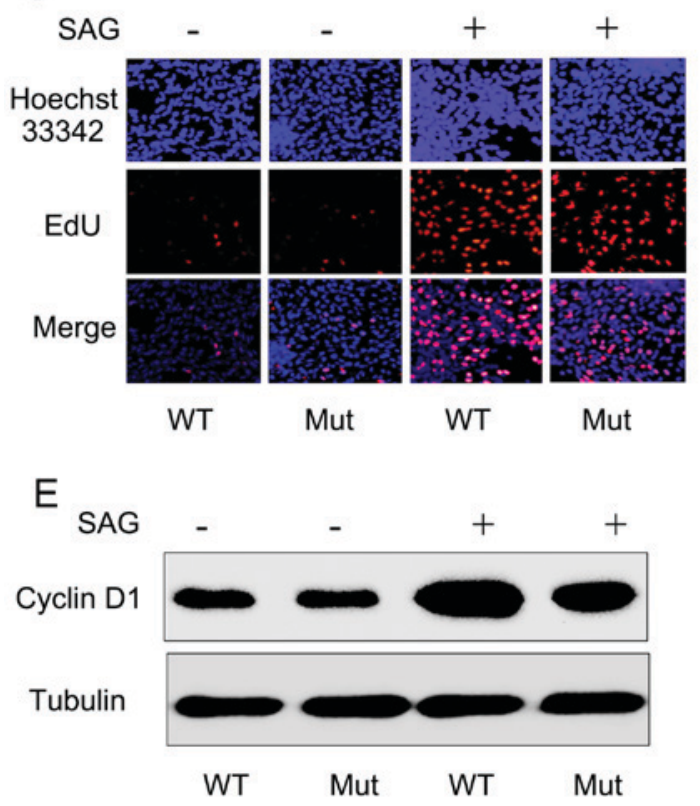

B

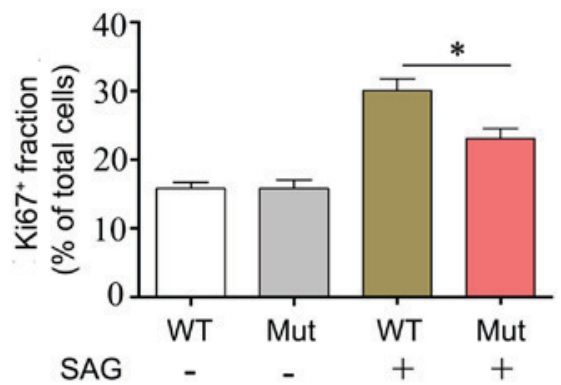

D

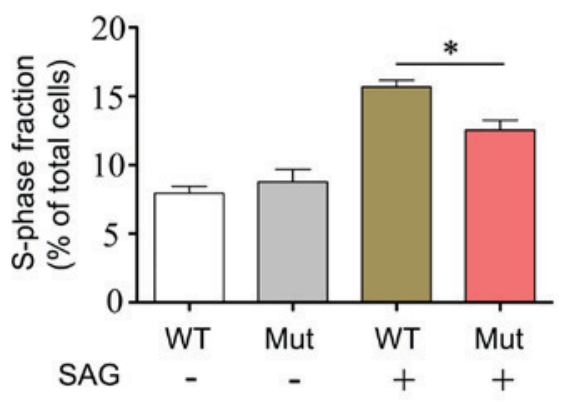

$\mathrm{F}$

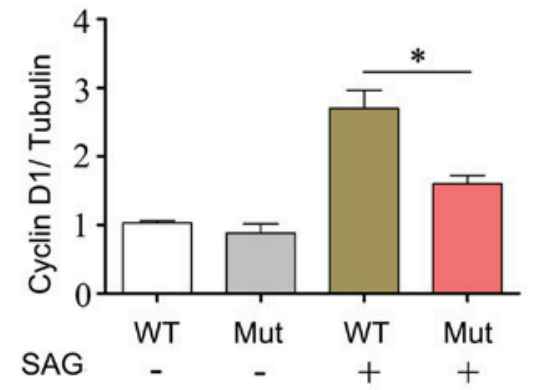

Figure 2. EVC c.343C >G mutation inhibits NIH3T3 cell proliferation. (A) Immunofluorescence staining demonstrating the amount of Ki67-positive cells in the WT or Mut group in the absence or presence of SAG. (B) Quantitative analysis of Ki67 fraction of total cells. Ki67-positive cells were stained red and nuclei were stained blue; original magnification, x100. (C) EdU assay indicating the percentage of S-phase cells in the WT or Mut groups treated with or without SAG. (D) Quantitative analysis of EdU assay. The S-phase cells were stained red and nuclei were stained blue; original magnification, x100. (E) Western blotting of the protein expression levels of cyclin D1 in WT or Mut cells in the absence or presence of SAG. (F) Quantitative analysis of western blotting. Tubulin was used as a loading control. Data are presented as the mean \pm standard error of the mean; ${ }^{*} \mathrm{P}<0.05$ vs. WT + SAG. EdU, 5-ethynyl-20-deoxyuridine; EVC, Ellis-van Creveld; Mut, EVC c.343C >G mutation; SAG, smoothened agonist; WT, wild-type.

Hh pathway (14-15). To confirm whether the EVC c.343C >G mutation affected the activity of the Hh pathway and investigate the association of the decrease in the expression level of cyclin D1 and Bcl2 proteins, a Gli1 luciferase reporter gene plasmid was used to determine the transcription activity of Gli1 which acts as an upstream effector of the Hh pathway. The results revealed that there was significantly reduced Gli1 luciferase reporter gene activity in the Mut group following $\mathrm{Hh}$ pathway activation by SAG treatment, compared with activity in the WT transfection group (Fig. 4A). This result suggested that EVC c.343C $>\mathrm{G}$ mutation decreased the transcriptional activity of Glil following $\mathrm{Hh}$ activation. In addition, western blotting results demonstrated that, compared with the WT group, the expression levels of the Gli1 protein were significantly decreased in the Mut group when the Hh pathway was activated by SAG (Fig. 4B and C).

Gli2 is the primary effector molecule of the Hh pathway. When the Hh pathway is in the resting state, full-length Gli2
$\left(\mathrm{Gli} 2^{\mathrm{ful}}\right)$ is cut by the proteasome to generate the repressor form of Gli2, Gli2 ${ }^{r}$, which inhibits the transcription of downstream target genes. When the Hh pathway is activated, $\mathrm{Gli}^{\text {ful }}$ is converted to its activated for $\mathrm{Gli}^{\mathrm{A}}$. A previous study demonstrated that EVC was required for Hh pathway to inhibit Gli2 $2^{\mathrm{r}}$ formation in cultured cells (15). To determine whether these processes were affected by EVC c.343C $>$ G mutation, a Gli2-Flag plasmid was constructed and transfected it into NIH3T3 cells to determine the levels of the two isoforms of Gli2 using western blotting. The results indicated that in the presence of SAG, the Gli2 ${ }^{\mathrm{r}}$-Flag/Gli2 ${ }^{\mathrm{ful}}$-Flag ratio was significantly increased in the Mut group compared with WT (Fig. 4D and E), which suggested that the suppressor form Gli2 ${ }^{\mathrm{r}}$ increased following the full-length Gli2 was cut and that EVC c.343C $>$ G mutation affected the Hh pathway.

Previous study has been demonstrated that Smo is upstream of EVC in the Hh pathway (15). When $\mathrm{Hh}$ is activated, EVC may form a protein complex with Smo to 

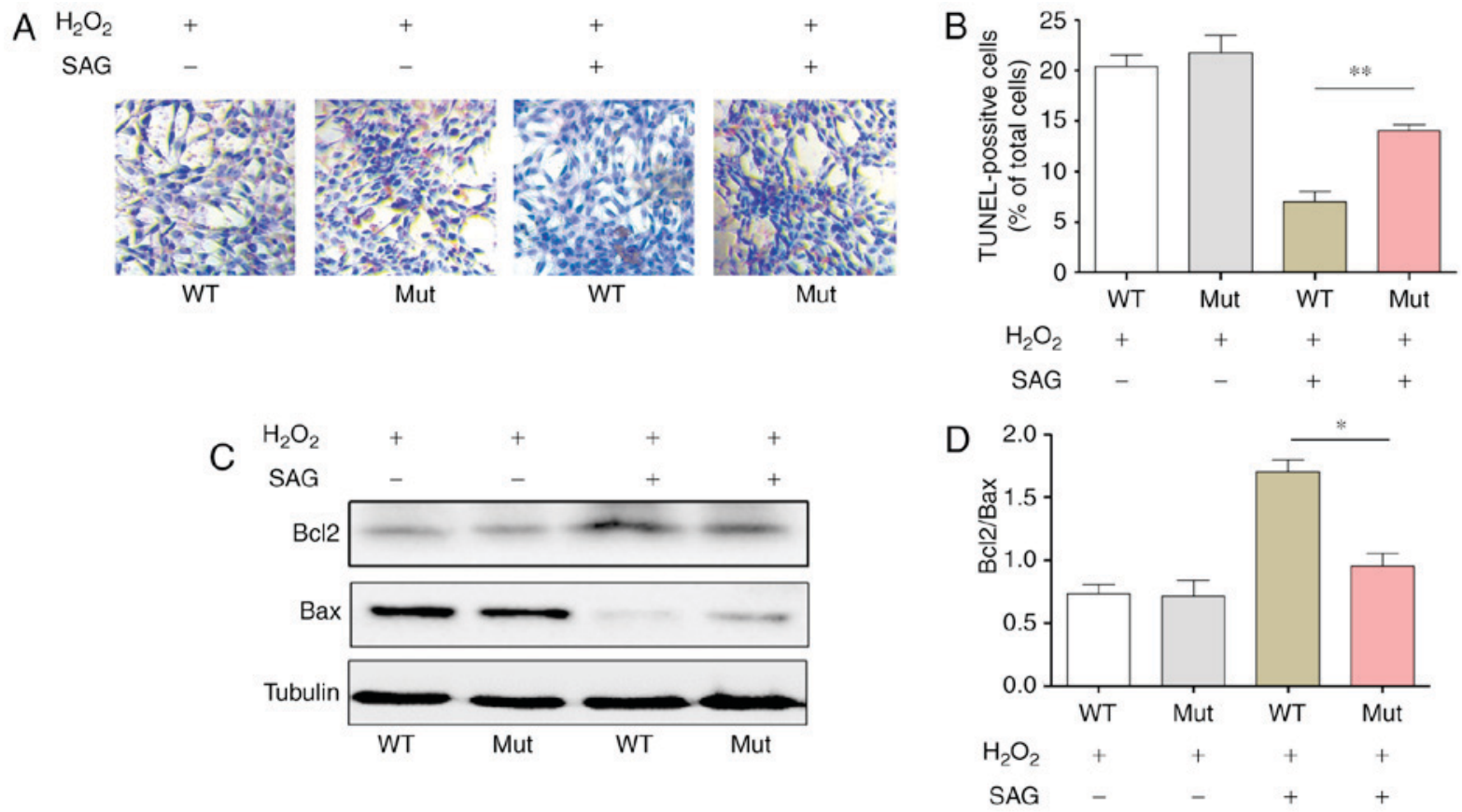

Figure 3. EVC c.343C $>$ G mutation increases apoptosis in NIH3T3 cells. (A) TUNEL assay demonstrating the ratio of apoptotic cells in WT and Mut groups following $\mathrm{H}_{2} \mathrm{O}_{2}$ induction in the absence or presence of SAG; original magnification, x200. (B) Quantiative analysis of TUNEL staining. (C) Western blotting and (D) quantitative analysis of the protein expression ratio of $\mathrm{Bcl} / \mathrm{Bax}$ following $\mathrm{H}_{2} \mathrm{O}_{2}$ induction with or without SAG treatment in the WT and Mut groups; tubulin was used as a loading control. Data are presented as the mean \pm standard error of the mean; ${ }^{*} \mathrm{P}<0.05$ and ${ }^{* * *} \mathrm{P}<0.01$ vs. WT $+\mathrm{SAG}$. Bax, B-cell lymphoma 2-associated X protein; Bcl2, B cell lymphoma 2; EVC, Ellis-van Creveld; Mut, EVC c.343C $>$ G mutation; SAG, smoothened agonist; WT, wild-type.

\section{A}
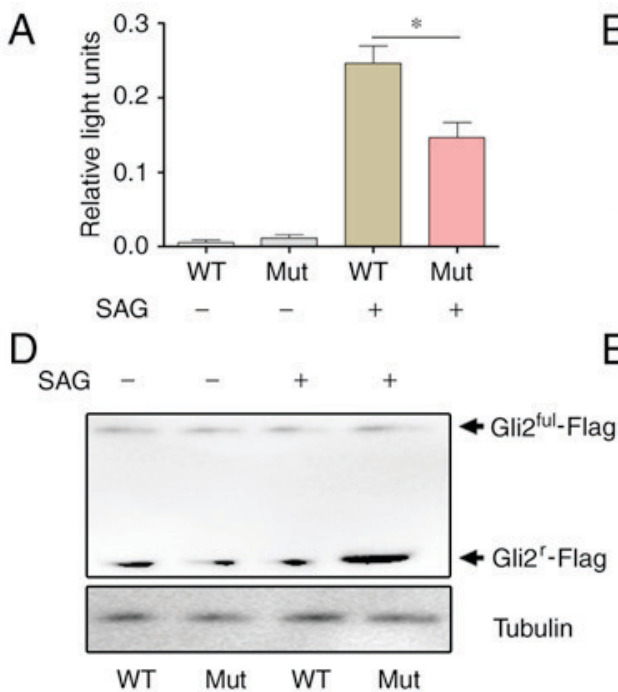

B

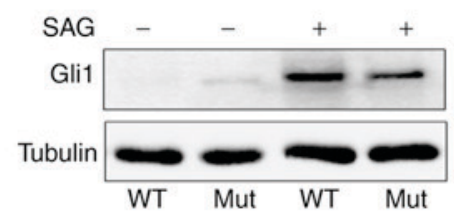

E

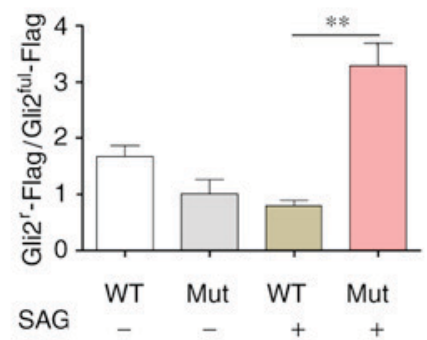

C

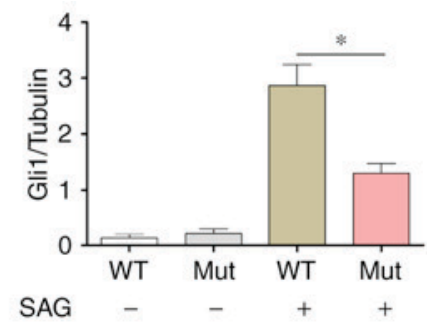

F

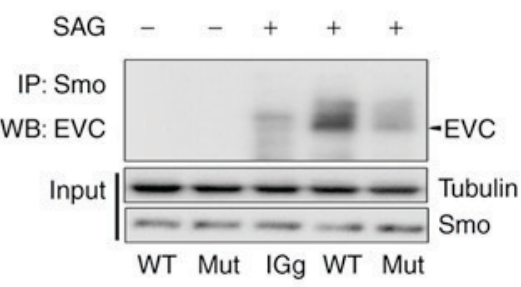

Figure 4. EVC c.343C>G mutation decreases the activity of the Hedgehog signaling pathway. (A) Luciferase reporter gene assay demonstrating Gli1 transcriptional activity with the indicated treatments. (B) Western blotting and (C) quantitative analysis indicating the expression of Gli1 protein in WT and Mut groups with or without SAG treatment. Tubulin was used as a loading control. (D) Western blotting and (E) quantitative analysis of full-length (Gli2 $2^{\text {ful }}$ ) and processed (Gli2 $2^{r}$ forms of Gli2 in WT and Mut groups in the absence or presence of SAG. (F) Representative blots of the interaction of EVC and Smo detected by co-immunoprecipitation. Data are presented as the mean \pm standard error of the mean; ${ }^{*} \mathrm{P}<0.05$ and ${ }^{* *} \mathrm{P}<0.01$ vs. WT with SAG. EVC, Ellis-van Creveld; Gli glioma-associated oncogene homolog; Mut, EVC c.343C >G mutation; SAG, smoothened agonist; Smo, smoothened; WT, wild-type.

transduce the signal intracellularly, leading to Gli activation (15). To investigate whether EVC c.343C $>\mathrm{G}$ mutation affected the interaction between Smo and EVC, co-immunoprecipitation was used for analysis and the results revealed that the binding between EVC and Smo in the Mut group was notably decreased compared with that in the WT group in the presence of SAG (Fig. 4F).

\section{Discussion}

Genetic variations serve important roles in the development of VSD. In the present study, 11 SNPs and one EVC genetic mutation were discovered in 65 cases of VSD. Following the Hardy-Weinberg equilibrium examination and Bonferroni correction, only the c. $1727 \mathrm{G}>\mathrm{A}$ SNP was identified as 
significantly positively associated with the development of VSD in a Chinese Han population. These results suggested that c. $1727 \mathrm{G}>\mathrm{A}$ may be an important disease-susceptible polymorphism site for the development of VSD. It has been reported that the $c .1727 \mathrm{G}>\mathrm{A}$ site may be associated with smoking-associated pancreatic cancer and male suicidal behavior $(28,29)$. In addition, PolyPhen-2 and MutationTaster software both predicted that this site was a pathogenic site and may alter the splicing site. Therefore, it was hypothesized that $\mathrm{c} .1727 \mathrm{G}>\mathrm{A}$ may be a potential susceptible gene maker for genetic diagnostics and targeted treatment of VSD.

A rare EVC c.343C $>$ G (p.L115V) mutation in a VSD subpopulation was detected. This mutation had not been reported in the 1000 Genomes database, the EVS database or the control group in the present study. Only the ExAC database reported two carriers among 4,327 East Asians. The frequency was very low, and the MAF was 0.0002, which supported the judgment of the mutations (30). This mutation was located in the conserved EVC coding sequences. PolyPhen-2 and MutationTaster software both predicted this to be a pathogenic site. The present study revealed that the EVC c.343C $>$ G mutation may affect Hh pathway activity by downregulating the binding between EVC and Smo, reducing the activity of the downstream Gli1 transcription factor, increasing the production of the Gli2 repressor form Gli2 and downregulating the expression levels of the downstream cyclin D1 and $\mathrm{Bcl} 2$ proteins. As a result, this mutation also reduced the anti-apoptotic ability of cells, caused cell cycle disorder in the transition from G1 to $\mathrm{S}$ phase in cells and reduced the proliferation level. Results from the present study demonstrated the association between Chinese Han patients with VSD and the EVC gene mutation and may be the first to systematically describe the molecular mechanism underlying the development of VSD caused by EVC mutations.

The development of VSD at the embryonic stage is associated with various mechanisms, of which abnormal SHF development is one of the primary mechanisms (31). Previous studies have revealed that inhibition of the Hh pathway may cause reduction of the Hh ligand Ptc in the SHF to inhibit cardiomyocyte proliferation and cause CHD phenotypes such as pulmonary vein atresia (16). In a cilia protein Meckel syndrome type 1 gene homozygous mutation mouse model, Hh pathway activity in the SHF of an embryonic mouse heart significantly decreased and reduced Glil expression led to abnormal development of the SHF region and caused atrioventricular septal defect (32). Results from these studies suggested that the Hh signaling pathway and development of the SHF in an embryonic stage heart were closely associated. A number of other studies also demonstrated that when the Hh pathway was activated, interference with or inhibition of EVC expression significantly decreased Glil expression and blocked $\mathrm{Hh}$ pathway activity to reduce cell proliferation in in vivo and in vitro experiments $(11,33)$. These results suggested that EVC was an activator molecule of the Hh pathway. Therefore, combined with the in vitro experiment results, the present study hypothesized that EVC mutations may cause a reduction in $\mathrm{Hh}$ pathway activity to inhibit the proliferation of SHF cells at the embryonic stage, thus causing abnormal heart development. These alterations may be one of the mechanisms underlying the development of VSD caused by EVC mutations.
As early as 2003, it was reported that the Hh pathway had anti-apoptotic functions and promoted cell survival during vertebrate development (34). Subsequent study revealed that the anti-apoptotic functions of $\mathrm{Hh}$ were through the inhibition of the mitochondrial pathway, which caused neuronal apoptosis resistance by regulating the expression ratio between the anti-apoptotic protein $\mathrm{Bcl} 2$ and the pro-apoptotic protein Bax (27). The present study demonstrated that the EVC c. $343 \mathrm{C}>\mathrm{G}$ mutation may block the activity of $\mathrm{Hh}$ signaling, thus reducing the $\mathrm{Bcl} 2 / \mathrm{Bax}$ ratio, activating the mitochondrial apoptosis pathway and reducing the anti-apoptotic functions of cells

Smo is an indispensable key member in the signal transduction of the Hh pathway. Previous studies indicated that the Hh pathway promoted the formation of a protein complex between phosphorylated Smo and EVC to activate downstream Gli family transcription factors and promote the transcription of downstream target genes $(13,15)$. Binding between EVC and Smo depends on the result of Hh pathway activation, which is consistent with the results of the present study in which there was a reduction in the binding between EVC-L115V and Smo that led to an increase in generation of the Hh pathway downstream effector factor Gli2 ${ }^{\mathrm{r}}$ and reduced the expression of genes associated with proliferation and anti-apoptosis.

In conclusion, results from the present study suggested that the EVC gene was the pathogenic gene in patients with VSD. The c. $1727 \mathrm{G}>\mathrm{A}$ polymorphism was a susceptible gene locus for the development of VSD. By affecting the activities of the Hh pathway, the EVC c.343C $>\mathrm{G}$ mutation may decrease $\mathrm{Bcl} 2$ expression, reduce the anti-apoptosis activity of cells, induce G1-to-S phase transition disorders in cells and reduce cell proliferation levels. The results may partially reveal the pathogenesis of cardiac defects in patients with EVC syndrome and provide new targets for the diagnosis and treatment of patients with VSD.

\section{Acknowledgements}

The authors would like to thank Xin Liu and Menglu Liu (Nanchang University, China) for assisting in laboratory work.

\section{References}

1. Pierpont ME, Basson CT, Benson DW Jr, Gelb BD, Giglia TM, Goldmuntz E, McGee G, Sable CA, Srivastava D and Webb CL; American Heart Association Congenital Cardiac Defects Committee, Council on Cardiovascular Disease in the Young: Genetic basis for congenital heart defects: Current knowledge: A scientific statement from the American Heart Association Congenital Cardiac Defects Committee, Council on Cardiovascular Disease in the Young: Endorsed by the American Academy of Pediatrics. Circulation 115: 3015-3038, 2007.

2. Serra-Juhé C, Cuscó I, Homs A, Flores R, Torán N and Pérez-Jurado LA: DNA methylation abnormalities in congenital heart disease. Epigenetics 10: 167-177, 2015.

3. Koefoed K, Veland IR, Pedersen LB, Larsen LA and Christensen ST: Cilia and coordination of signaling networks during heart development. Organogenesis 10: 108-125, 2014.

4. Muntean I, Toganel R and Benedek T: Genetics of congenital heart disease: Past and present. Biochem Genet 55: 105-123, 2017.

5. Chen D, Qiao Y, Meng H, Pang S, Huang W, Zhang H and Yan B: Genetic analysis of the TBX3 gene promoter in ventricular septal defects. Gene 512: 185-188, 2013. 
6. Leirgul E, Fomina T, Brodwall K, Greve G, Holmstrøm H, Vollset SE, Tell GS and Øyen N: Birth prevalence of congenital heart defects in Norway 1994-2009-a nationwide study. Am Heart J 168: 956-964, 2014

7. Gittenberger-de Groot AC, Calkoen EE, Poelmann RE, Bartelings MM and Jongbloed MR: Morphogenesis and molecular considerations on congenital cardiac septal defects. Ann Med 46: 640-652, 2014

8. Sund KL, Roelker S, Ramachandran V, Durbin L and Benson DW: Analysis of Ellis van Creveld syndrome gene products: Implications for cardiovascular development and disease. Hum Mol Genet 18: 1813-1824, 2009.

9. Hills CB, Kochilas L, Schimmenti LA and Moller JH: Ellis-van Creveld syndrome and congenital heart defects: Presentation of an additional 32 cases. Pediatr Cardiol 32: 977-982, 2011

10. Caparrós-Martín JA, De Luca A, Cartault F, Aglan M, Temtamy S, Otaify GA, Mehrez M, Valencia M, Vázquez L, Alessandri JL, et al: Specific variants in WDR35 cause a distinctive form of Ellis-van Creveld syndrome by disrupting the recruitment of the EvC complex and SMO into the cilium. Hum Mol Genet 24: 4126-4137, 2015.

11. Pacheco M, Valencia M, Caparrós-Martín JA, Mulero F, Goodship JA and Ruiz-Perez VL: Evc works in chondrocytes and osteoblasts to regulate multiple aspects of growth plate development in the appendicular skeleton and cranial base. Bone 50: 28-41, 2012.

12. Hui $\mathrm{C}$ and Angers S: Gli proteins in development and disease Annu Rev Cell Dev Bi 27: 513-537, 2011.

13. Briscoe $\mathrm{J}$ and Thérond PP: The mechanisms of Hedgehog signalling and its roles in development and disease. Nat Rev Mol Cell Bio 14: 416-429, 2013

14. Ruiz-Perez VL, Blair HJ, Rodriguez-Andres ME, Blanco MJ, Wilson A, Liu YN, Miles C, Peters H and Goodship JA: Evc is a positive mediator of Ihh-regulated bone growth that localises at the base of chondrocyte cilia. Development 134: 2903-2912, 2007.

15. Yang C, Chen W, Chen Y and Jiang J: Smoothened transduces Hedgehog signal by forming a complex with Evc/Evc2. Cell Res 22: 1593-1604, 2012.

16. Dyer LA and Kirby ML: Sonic hedgehog maintains proliferation in secondary heart field progenitors and is required for normal arterial pole formation. Dev Biol 330: 305-317, 2009.

17. Liu X, Li M, Peng Y, Hu X, Xu J, Zhu S, Yu Z and Han S: miR-30c regulates proliferation, apoptosis and differentiation via the Shh signaling pathway in P19 cells. Exp Mol Med 48: e248, 2016.

18. Washington Smoak I, Byrd NA, Abu-Issa R, Goddeeris MM Anderson R, Morris J, Yamamura K, Klingensmith J and Meyers EN: Sonic hedgehog is required for cardiac outflow tract and neural crest cell development. Dev Biol 283: 357-372, 2005.

19. Wan R, Guo R, Chen C, Jin L, Zhu C, Zhang Q, Xu Y and Li S: Urocortin increased LPS-induced endothelial permeability by regulating the cadherin-catenin complex via corticotrophin-releasing hormone receptor 2. J Cell Physiol 228: 1295-1303, 2013

20. Liu X, Chen L, Ge J, Yan C, Huang Z, Hu J, Wen C, Li M, Huang D, Qiu Y, et al: The Ubiquitin-like protein FAT10 stabilizes eEF1A1 expression to promote tumor proliferation in a complex manner. Cancer Res 76: 4897-4907, 2016.

21. Peng X, Shao J, Shen Y, Zhou Y, Cao Q, Hu J, He W, Yu X, Liu X, Marian AJ and Hong K: FAT10 protects cardiac myocytes against apoptosis. J Mol Cell Cardiol 59: 1-10, 2013.

22. Yuan R, Wang K, Hu J, Yan C, Li M, Yu X, Liu X, Lei J, Guo W, $\mathrm{Wu} \mathrm{L}$, et al: Ubiquitin-like protein FAT10 promotes the invasion and metastasis of hepatocellular carcinoma by modifying $\beta$-catenin degradation. Cancer Res 74: 5287-5300, 2014.
23. Liu T, Yu X, Li G, Yuan R, Wang Q, Tang P, Wu L, Liu X, Peng $X$ and Shao J: Rock2 regulates Cdc25A through ubiquitin proteasome system in hepatocellular carcinoma cells. Exp Cell Res 318: 1994-2003, 2012

24. Nuño-Arana I, Sahagún-Núñez Vdel R, Muñoz-Valle JF, Sandoval L, Pinto-Escalante D, Páez-Riberos LA, Lazalde B, Maldonado-González M and Rangel-Villalobos H: Distribution of three SNPs related to low bone mineral density in Amerindian groups and Mestizos from Mexico. Am J Hum Biol 24: 569-572, 2012 .

25. Goddeeris MM, Schwartz R, Klingensmith $\mathrm{J}$ and Meyers EN: Independent requirements for Hedgehog signaling by both the anterior heart field and neural crest cells for outflow tract development. Development 134: 1593-1604, 2007.

26. Shahi MH, Afzal M, Sinha S, Eberhart CG, Rey JA, Fan X and Castresana JS: Regulation of sonic hedgehog-GLI1 downstream target genes PTCH1, Cyclin D2, Plakoglobin, PAX6 and NKX2.2 and their epigenetic status in medulloblastoma and astrocytoma. Bmc Cancer 10: 614, 2010.

27. Xia YP, Dai RL, Li YN, Mao L, Xue YM, He QW, Huang M, Huang Y, Mei YW and $\mathrm{Hu}$ B: The protective effect of sonic hedgehog is mediated by the phosphoinositide [corrected] 3-kinase/AKT/Bcl-2 pathway in cultured rat astrocytes under oxidative stress. Neuroscience 209: 1-11, 2012.

28. Tang H, Wei P, Duell EJ, Risch HA, Olson SH, Bueno-de-Mesquita HB, Gallinger S, Holly EA, Petersen G, Bracci PM, et al: Axonal guidance signaling pathway interacting with smoking in modifying the risk of pancreatic cancer: A gene- and pathway-based interaction analysis of GWAS data. Carcinogenesis 35: 1039-1045, 2014.

29. Must A, Kõks S, Vasar E, Tasa G, Lang A, Maron E and Väli M: Common variations in $4 \mathrm{p}$ locus are related to male completed suicide. Neuromol Med 11: 13-19, 2009.

30. Karki R, Pandya D, Elston RC and Ferlini C: Defining 'mutation' and 'polymorphism' in the era of personal genomics. BMC Med Genomics 8: 37, 2015.

31. Meilhac SM, Esner M, Kelly RG, Nicolas JF and Buckingham ME: The clonal origin of myocardial cells in different regions of the embryonic mouse heart. Dev Cell 6: 685-698, 2004.

32. Burnicka-Turek O, Steimle JD, Huang W, Felker L, Kamp A, Kweon J, Peterson M, Reeves RH, Maslen CL, Gruber PJ, et al: Cilia gene mutations cause atrioventricular septal defects by multiple mechanisms. Hum Mol Genet 25: 3011-3028, 2016.

33. Nakatomi M, Hovorakova M, Gritli-Linde A, Blair HJ, MacArthur K, Peterka M, Lesot H, Peterkova R, Ruiz-Perez VL, Goodship JA and Peters H: Evc regulates a symmetrical response to Shh signaling in molar development. J Dent Res 92: 222-228, 2013.

34. Thibert C, Teillet MA, Lapointe F, Mazelin L, Le Douarin NM and Mehlen P: Inhibition of neuroepithelial patched-induced apoptosis by sonic hedgehog. Science 301: 843-846, 2003.

This work is licensed under a Creative Commons Attribution-NonCommercial-NoDerivatives 4.0 International (CC BY-NC-ND 4.0) License. 